\title{
Is Liberal Education Valuable? Undergraduate Students Raise their Opinions
}

\author{
By Hilda Patino Dominguez*
}

This exploratory qualitative study focused on the free responses that undergraduate students gave to the question: "Should have learned something valuable in this course, what was it?". This question is part of a survey that intended to obtain the views of the students on courses of humanistic character as part of their college education. Knowing what students think has been a constant concern to the Iberoamerican University, which academic plans include four humanistic courses for all careers. The courses' purpose is to contribute to the integral/liberal education of students. There were collected 4625 valid student responses during the spring and autumn periods 2010 and spring 2011, covering the entire population given at that time. For the data analysis a mixed approach (qualitative and quantitative analysis) was used. The research offers a way of understanding liberal/ humanistic education courses from the perspective of the students and challenge college professors to look for different alternatives to promote meaningful learning.

Keywords: college education, humanism, humanistic courses, liberal education, students

\section{Introduction}

Liberal education is a constant concern to the higher education institutions in Mexico and in the world. The phenomenon of globalization, which appears to favor individualistic approaches, the quest for personal gain while neglecting the social demands and humanistic currents, makes us a call to retrieve the task of forming individuals with a critical and committed awareness with common causes, revitalize a sense of solidarity and interdependence; promote the values of responsibility, generosity, compassion and cooperation, which are based on the principle of recognizing human dignity beyond cultural differences, sexual orientation, religion, etc. Within a society that is fragmented, humanistic thought represents the desire to recover the moral values and to educate citizens for a better society. Liberal education thus becomes a civilization project that concerns undoubtedly to educational institutions.

The Iberoamerican University defines itself in its basic documents, as an institution of higher education which promotes an "integral humanism" as a general educational aim. The educational model fosters interdisciplinary approaches through a flexible curriculum, which is intended to strengthen formative objectives of liberal education.

This research takes as a benchmark previous research studies that have been conducted to evaluate the effectiveness of liberal education courses in the

\footnotetext{
${ }^{*}$ Program Coordinator, Iberoamerican University, Mexico.
} 
Iberoamerican University. Our research asks undergraduate students' opinion about the value of the liberal education courses they were enrolled during 2010 and 2011.

A total of 4,625 written anonymous responses were examined and interpreted trough a qualitative methodology, in order to develop fundamental categories, with their respective subcategories (codes) that made possible to build up the concept of "valuable learning" from the perspective of college students.

\section{Project Objectives}

1. To build the concept of "valuable learning" from the various meanings that college students gave to it when they were asked about their opinion of the valuable things they learned in liberal education courses they have taken as part of their curriculum.

2. To approach to the ways students think and feel about liberal education, so those educational approaches with greater learning potential could be strengthened.

The instrument used to collect students' opinions about the valuable learning of the courses, was an assessment questionnaire, to which an open question (question number 17) was added, namely:

"Should you have learned something valuable in this course, what was it?"

Collecting, classifying, analyzing and interpreting multiple answers that students gave to this question allowed a better understanding of the impact of the liberal education courses that the Iberoamerican University currently offers to all undergraduate students as the main part of their General Education.

\section{Theoretical Considerations}

\section{The Need for Liberal Education at University Level}

Today, next to a growing trend towards specialization, coexists a major concern for not losing sight of the whole that allows us to connect the parts to the whole and the whole to the parts. Given the magnitude of the problems caused by technological advances, Morin (2001) emphasizes the need for a kind of education aimed to promote comprehensive knowledge that allows individuals to be able to address global and fundamental problems, and to register the partial and local knowledge in a broader context that includes ethical considerations. Among other consequences, this means that education must have the task of developing skills to integrate the information into an overall perspective, being this the liberal education approach. 
Without denying the role and usefulness of technical specialization, one cannot just stick with a "compartmentalized" knowledge, because this kind of knowledge has made us to lose the perception of the whole. It has led us to enormous progress yet, it has become also a threat to the survival of human species in many senses. The general culture approach of liberal education encourages the pursuit of contextualization of any information or idea and to reflect on its ethical consequences, meanwhile, the scientific knowledge and disciplinary approaches tend to parcel and disengage knowledge, making it increasingly difficult to contextualize.

In Morin's opinion, this trend, typical of the twentieth century, has brought a huge blindness to global problems, so from now on, education should strive to complement a thought that splits off and reduces reality with a thought that unifies and relates, so that individuals can be more aware of their own human condition, from a complex and multidimensional perspective. In Morin's opinion, this trend, typical of the twentieth century, has brought a huge blindness to global problems, so from now on, education should strive to complement a thought that splits off and reduces reality with a thought that unifies and relates, so that individuals can gain in awareness of their own human condition, from a complex and multidimensional perspective.

Facing the problem of scientific and technological knowledge in the globalization era, liberal education sustains the importance of the inalienable dignity of human beings, and it is concerned about their wellbeing, their feelings, needs and expectations, and their human development in general. Liberal education also assigns a high value to the development of critical thinking, creativity and curiosity, and favors discussion of ethical implications to individuals, as well as searching relationships among disciplines, so thanks to liberal education we can gain perception of the whole above specialized and fragmented knowledge.

Liberal education sustains a philosophical conception of the individual as subject-agent, endowed with free will. Thanks to a free and rational consciousness, the human being is capable of acting intentionally. It is considered that education is an intentional process aimed to understanding, affirming and transforming of the world and the individual itself. So, for example, López Calva affirms that the process of teaching and learning is essentially a process of "human encounter" in which an attentive, intelligent and reasonable dialogue takes place, as well as a review of the various aspects of reality that are studied with the intention of expanding the "horizon of understandings, meanings and values involved in it" (1996: II) and, concomitantly, of acquiring a greater self-appropriation.

\section{Conceptions of Learning}

Marton and Säljö (1976a, 1976b; Marton, Hounsell, \& Entwistle, 1984), are part of a group of Swedish researchers known as the "Gothenburg Group" dedicated, since 1970s, to qualitative research about the way people learn. In 
their methodological approach, these researchers privilege a phenomenological approach to describe the different ways apprentices approach new materials in order to learn them. The work of Marton and Säljö with college students concluded that there are different levels of learning, depending on the intention of the learner. The styles of processing information can be superficial or deep, and therefore, college students can be classified as superficial (surface) or deep learners. This is known as the theory of the "approaches to learning":

- Surface/Superficial Learning. In this approach, the student focuses on memorizing the material to answer questions without trying to integrate the elements or principles or concepts. He/she perceives the assignment of learning as an external and alien imposition, so his/her intention is only to comply with the request.

- Deep Learning. In this approach the student directs his/her attention to the meaning of the material given, trying to discover the relationships between the elements that constitute the whole, reflecting on the logic of the arguments, and relating the content to everyday life situations if possible, with the intention to gain a deeper a long lasting understanding of the matter.

This distinction of the Swedish authors, as a result of their empirical study, has been very useful for future research, such as the work of Bain (2004) and Biggs (2008), among many others. Also, this theory is more appropriate to the purpose of the present research, which is aimed to build the concept of "valuable learning experience" through the expressions of the students, who qualify what they obtain from the liberal education courses.

In the present work we addressed a qualitative approach in order to describe and interpret the concept of valuable learning. The research has been done inductively, through the construction of analytical categories based on the various expressions of the students. The data was gathered through anonymous and voluntary testimonies that students wrote on the assessment questionnaires. The research team gathered and analyzed a total of 4,625 responses given by approximately 3,600 students during 2010 and 2011.

\section{Study Methodology}

To carry out this research, it was followed a qualitative methodology, which was complemented by a quantitative analysis of the data. As it has been said, it was conducted an inductive analysis of the voluntary and anonymous responses to the open question No. 17 of the questionnaire of student assessment: "In case that you have learned something valuable in this course, what was it?".

The task of the research team was, mainly, developing the fundamental analytical categories that made possible to interpret and build up the concept of valuable learning in the liberal education courses through the perception of undergraduate students who answered the cited question. 
In order to achieve this, the research team gathered a total of 4,625 responses that were distributed per term, as follows:

- Spring Term 2010: 1,579

- Fall Term 2010: $\quad 1,590$

- Spring Term 2011: 1,456

- Total: $\quad \mathbf{4 , 6 2 5}$

The sample studied is the result of the assessment of 32 diverse liberal education courses in which undergraduate students were enrolled at the moment in the Iberoamerican University of Mexico City.

As is known, in qualitative methodology, researchers are committed to a constant review of back and forth between the data and the analytical theoretical conceptualizations which results in the creation of new categories, or reformulation and even removal of some of them in the research process itself.

In some cases it was not possible to classify a response in any way, so the research team decided to open a new code: "NC", or "not classifiable", which was used in 530 of the 4,625 responses studied, in such a way that a total of 4,095 answers was remained as valid.

It has to be pointed out that in the classification process it was found that one student frequently poured two or more ideas corresponding to different categories. In these cases, the answers were divided, so that the same individual may have two or more responses. That is the reason why in the final counting presented here, the unit of measure was responses, not individuals.

The process of establishing and reviewing categories was the result of a combination of individual and team work.

It is worth noting that one of the biggest problems facing qualitative research is the subjectivity that is involved in interpreting, classifying and categorizing information. Thus, to avoid this as much as possible, the research team used two major strategies:

- The classification that was made by an assistant research outside the team.

- The work of peer review within the same team.

As for the first strategy, it was used to establish a point of view outside the research team, in order to ratify or, if such was the case, to change categorizations. But the most helpful strategy was the assessment that team members made to each other during peer and group discussion sessions.

Once agreement was reached about the 4,625 responses' categorization, the research team proceeded to do an analysis and detailed interpretation of responses within each category, in order to achieve sub categorization that allowed developing the discourse of each particular category and a semantic map of its narrative. As expected in qualitative analysis, during this process the 
research team returned to discuss, reclassify and reassign some answers, until all responses were finally classified in categories and subcategories. Each interpretation was reviewed and adjusted by the researchers working as a team, so teamwork was essential to achieve the objective.

\section{Key Findings of the Research}

From student responses' interpretation, eight broad categories corresponding to the valuable lessons they perceived in the liberal education courses were finally established. These eight major categories are:

1. Appreciating, respecting and learning about diversity (people, cultures, traditions and religions).

2. Reflecting on oneself, the meaning of life and the humanity.

3. Expanding knowledge and acquiring new perspectives from other disciplinary fields.

4. Bonding with different disciplines to own.

5. Discovering new forms of interaction and coexistence with others.

6. Developing social commitment.

7. Acquiring an ethical perspective.

8. Developing critical thinking.

The eight general categories represent the first conceptual "family" groups whose central meaning binds different expressions.

The following briefly describes each of these eight categories with their assigned subcategories.

\section{Category 1: Appreciating, Respecting and Learning about Diversity (people, cultures, traditions and religions)}

"Tolerance towards others and be open to dialogue"

(Anonymous student's response)

This category had a total of 540 entries. It grouped those students' expressions that referred to respecting different opinions and ideologies, being open to change and new ideas, appreciating equality and valuing diversity, respecting interpersonal relationships, meeting and interacting with peers of different cultures, valuing human rights, appreciating indigenous cultures, valuing Mexico's cultural diversity and having an openness to different religious traditions. The information is presented graphically in Figure 1. 
Figure 1. Category 1: Appreciating, Respecting and Learning about Diversity

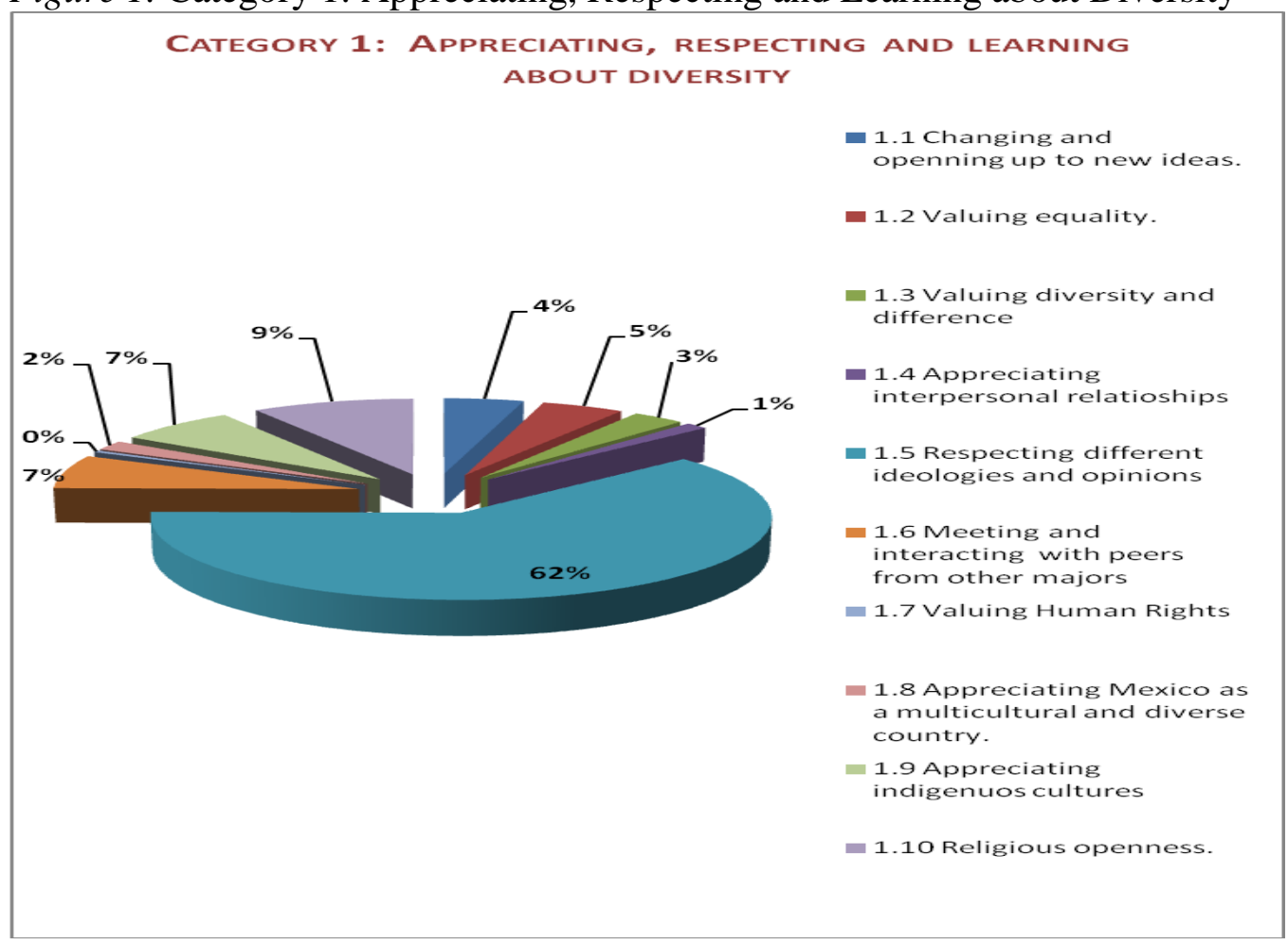

\section{Category 2: Reflecting on Oneself, the Meaning of Life and the Humanity}

"I like the fact truly learn about topics that are interesting and make you think about the world around you, a bit like trying to find answers to questions you've always had."

(Anonymous student's response)

This category grouped a total of 1339 entries. Those expressions of students referred to the knowledge and valuation of human beings, human life, and related aspects were classified within it. The subcategories have to do with expressions such as: knowing and growing as a person; reflecting on the meaning of life, reflecting on the issues of death and evil; caring for the planet and human existence, awareness of human rights; reflecting on relationships and sexuality; valuing people's dignity, considering the importance of health as a human value; discovering the importance of art, philosophy and spirituality for human existence, among others. The information is presented graphically in Figure 2. 
Figure 2. Reflecting on Oneself, the Meaning of Life and Humanity

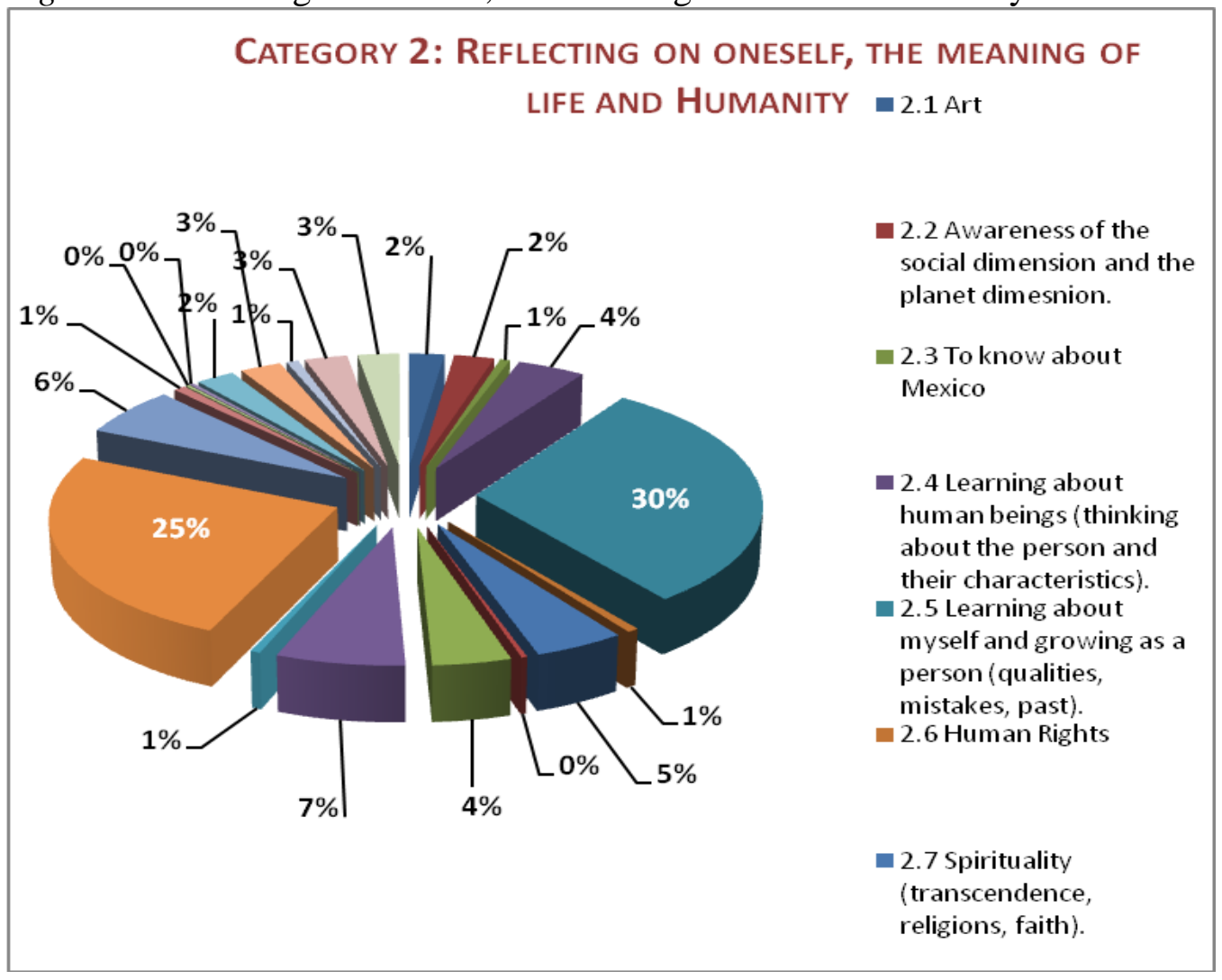

\section{Category 3: Expanding Knowledge and Acquiring New Perspectives from Other Disciplinary Fields}

"The course expanded the horizons of what I know and what I was interested in. It was like traveling in many ways."

(Anonymous student's response)

This category included a total of 1,545 entries. Assimilating and expanding one's knowledge, developing skills and acquiring attitudes and values are the most obvious goals of any course at undergraduate level.

By far, this category was first in the opinion of the students, which shows the high value given to acquiring knowledge and to every new understanding that may expand students intellectual horizons. Thanks to this new learning, it is possible to change one own conception of reality and one can go further, discovering, experiencing, and even more, enjoying being in the world. It is not only a matter of acquiring disjointed information but to make sense of it, to establish relationships with prior knowledge and with daily life experiences, so it can be transformed into meaningful learning. Expanding horizons of knowledge involves constructing new meanings and appropriating reality in a certain way.

This category was built by 30 sub-categories referred to those students' expressions linked to acquisition of new knowledge from a wide range of 
subjects that are offered in the field of humanities. The information is shown graphically in Figure 3.

Figure 3. Category 3: Expanding Knowledge and Acquiring New Perspectives from Other Discipline Fields

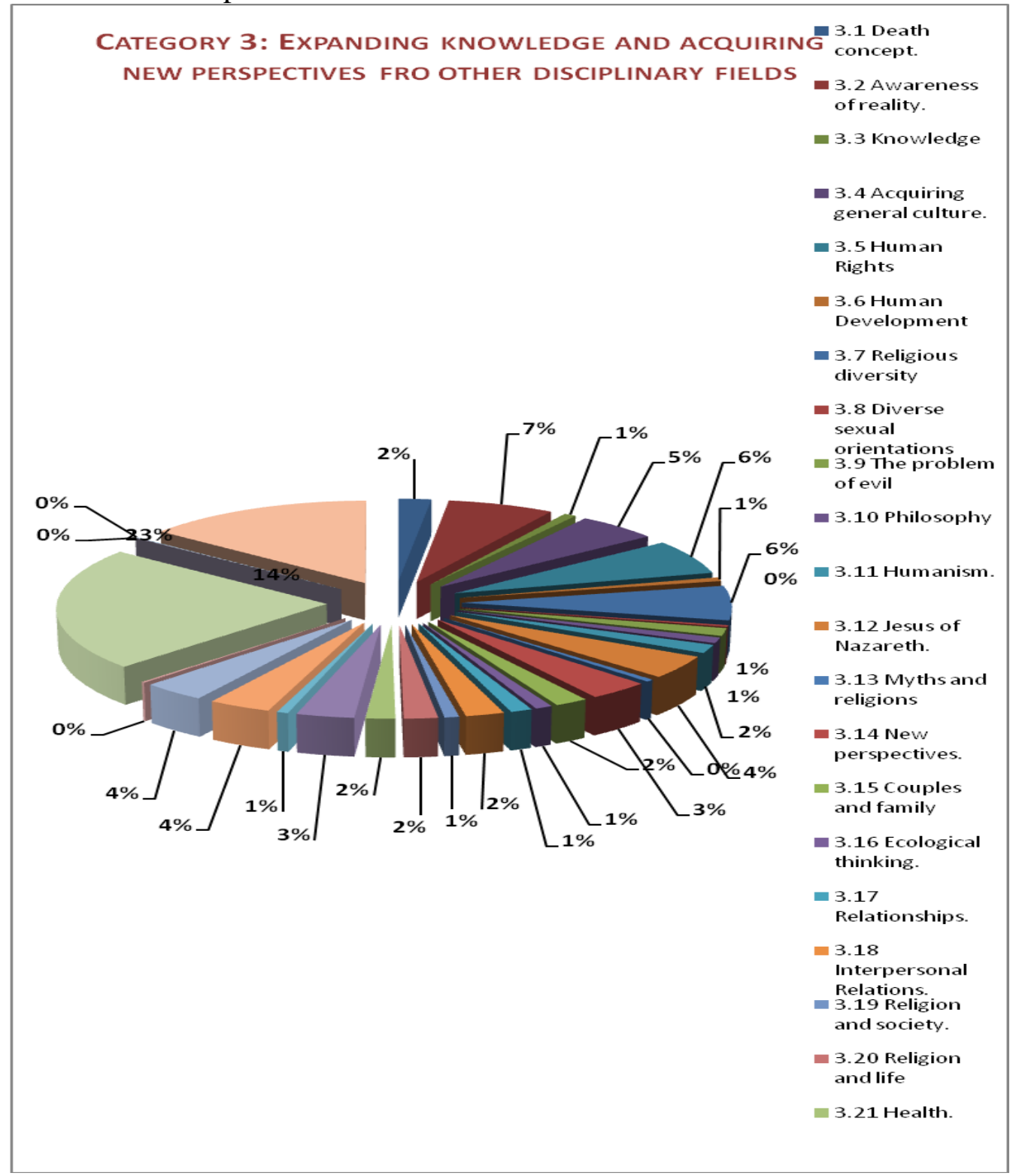

\section{Category 4: Bonding With Different Disciplines to Own}

"And (in this course) I realized that there are other different worlds outside mine, and as future Marketing Professional, it was necessary for me to know them."

(Anonymous student's response) 
This category was constructed by a total of 44 expressions. One feature, and arguably one of the virtues, of the current model in liberal education courses at the Universidad Iberoamerican, is that groups are formed with students from all majors offered by the university. This heterogeneity in classroom fosters coexistence of students with different academic backgrounds and different perspective of professional development, and obviously different personal interests.

The workflow generated in these liberal education courses allows the exchange of points of view among students, which favors, in turn, appreciating more clearly the link between one's own discipline and the other disciplinary fields. Sharing different technical languages and points of view also trains students to teamwork, a very useful competence later on, in the real professional life. The information is shown graphically in Figure 4.

Figure 4. Category 4: Bonding With Different Disciplines to Own

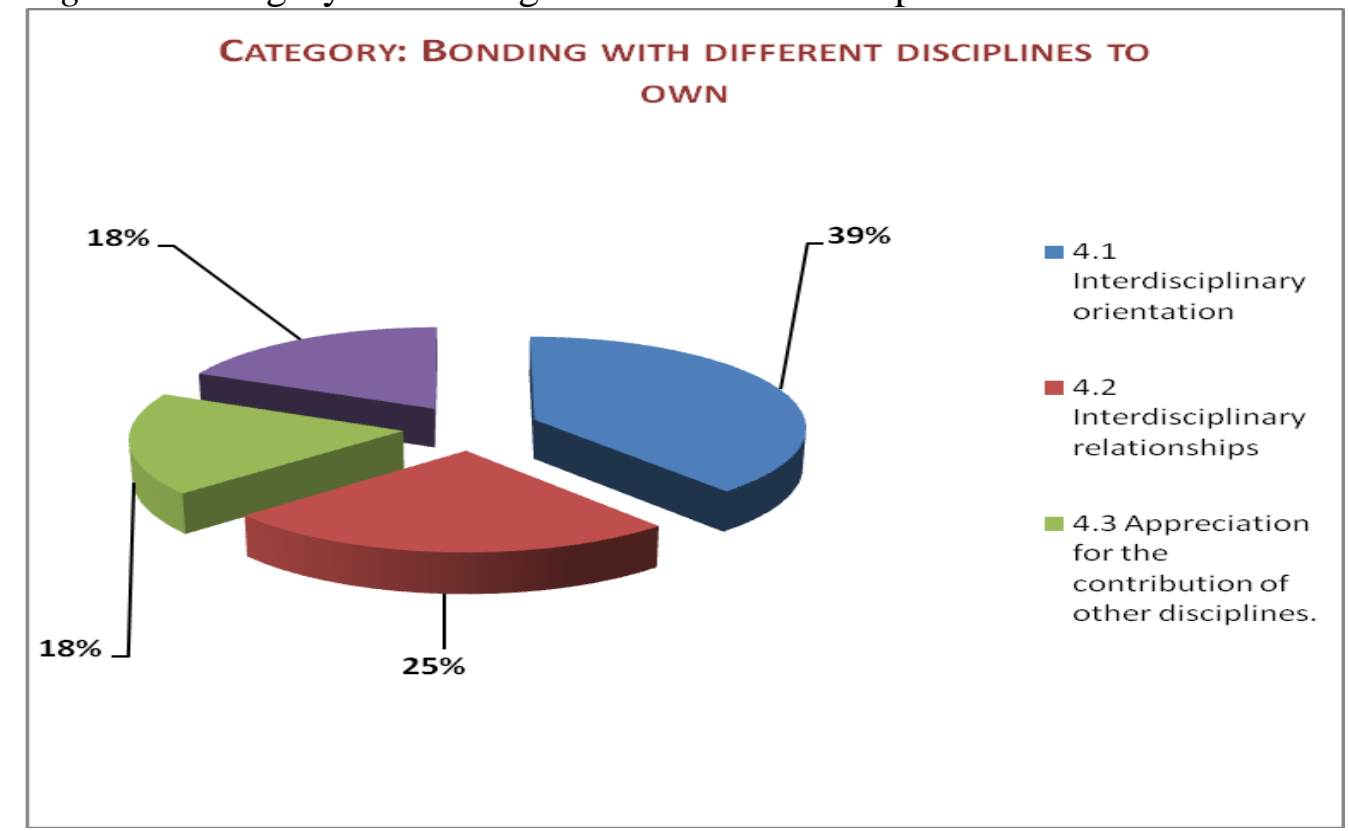

\section{Category 5: Discovering New Forms of Interaction and Coexistence with Others}

"I learned to listen to others and to know my classmates better than I did in another courses".

(Anonymous student's response)

This category was built upon 152 entries. Students' responses that were grouped here in reference to communication, dialogue, coexistence, integration capability, human interaction and human relationships, tolerance and solidarity among others, as examples of valuable learning obtained in their liberal education courses. As can be seen, this kind of learning is referred to the promotion of values, attitudes and skills that are clearly differentiated of a 
traditional perspective that focus on acquisition of theoretical knowledge. The information is shown graphically in Figure 5.

Figure 5. Category 5: Discovering New Forms of Interaction and Coexistence with Others

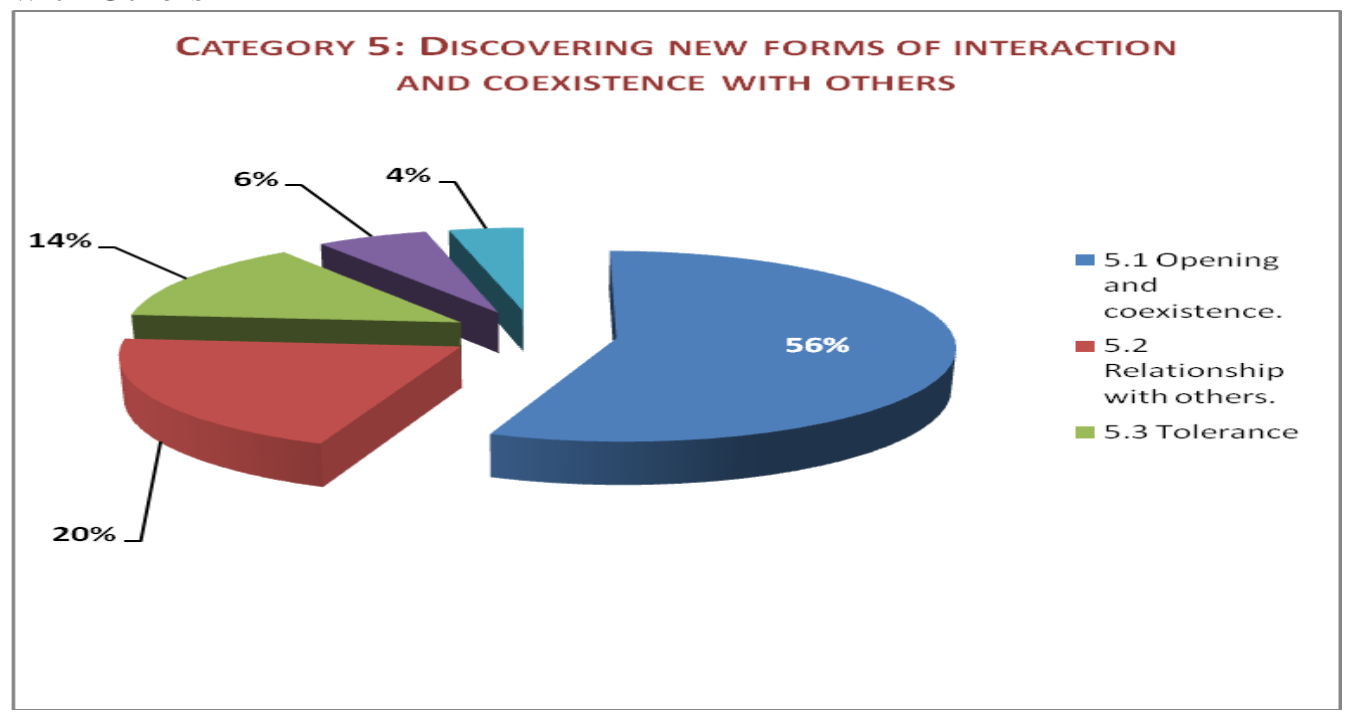

\section{Category 6: Developing Social Commitment}

"(In this class) I learned that what happens in the world goes beyond you and your own life, and that you should be mobilized to contribute to a change".

(Anonymous student's response)

The set of entries of Category 6 was formed with expressions that could be interpreted as a "sense of social commitment", counting a total of 167 entries. The findings made by the students during the learning process lead them to realize that the study of the sociocultural reality promotes a clearer understanding of the environment in which they live and the problems that they have to face, especially in a developing country such as Mexico. In greater or lesser degree, some students felt the need to change that part of social reality they reject, namely: injustice, poverty, and unemployment, lack of water, pollution, and other important big social problems.

The pedagogical method of the liberal education courses uses reflection about action through a personal process in which the particular triad: "watching-judging-acting" is a way to examine reality and to find out the best ways to participate in changes. Hence, some students statements express a very general wish to participate in change, although it is not very clear what to do and how to do it.

An intermediate level of students' responses makes proposals for a more specific action in which a recipient can be seen clearly. It is not just the manifest intention to influence reality, but to offer solutions to situations 
affecting those populations that are recognized as violated in their living conditions, their rights or their own integrity.

Finally, there are students who propose clear actions to take, thus confirming that some of them (a very few, indeed) have developed the ability to indicate alternative actions to help to improve the living conditions of the most disadvantaged sections of society. This small group of students represents a substantive element of achievement of the major liberal education goals in the Iberoamerican University. The information is shown graphically in Figure 6.

Figure 6. Category 6: Developing Social Commitment

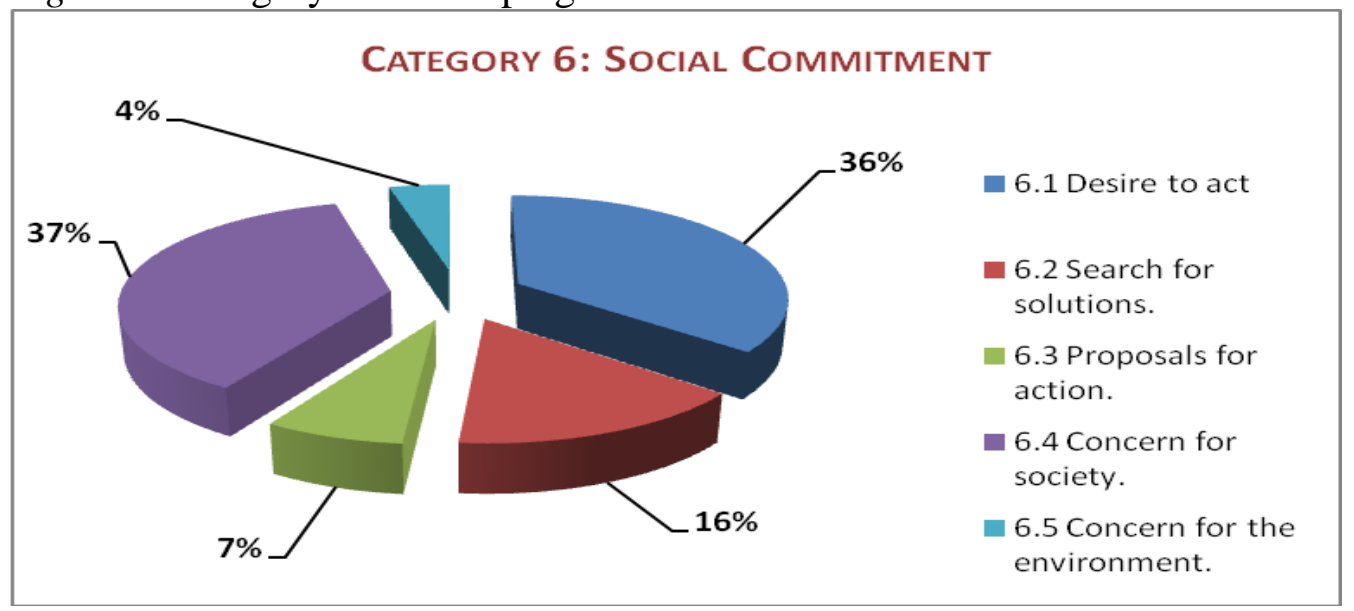

\section{Category 7: Acquiring an Ethical Perspective}

"(I learned)... to think about my actions before making a decision so I can see the possible consequences; and based on that, do not hurt others with my decisions."

(Anonymous student's response)

"It's a question of congruence between my values and principles and my actions."

(Anonymous student's response)

This category was built upon a total of 155 entries. It grouped expressions where explicit reference to ethics were made, as well as reflection on freedom and responsibility, the problem of evil, the values, the meaning of human dignity and, in general, everything that have to do with the ethical/moral experiences of students.

It should be noted that one of the main interests of liberal education is to promote the moral development of the individuals, in order to achieve an autonomous decision making, guided by reason. Individuals with high moral development make decisions based on universal principles that they have taken as their own, and therefore, they always consider the consequences of a decision, not only for a particular individual but for humanity in general. These guiding moral principles have to do with the affirmation of human dignity and 
the affirmation of basic fairness and equality among human beings.

It must be pointed out that developing an ethical perspective in college students is a key priority for liberal education, so it is worrying that there are so few explicit mentions made by students. The information is shown graphically in Figure 7.

Figure 7. Category 7: Acquiring an Ethical Perspective

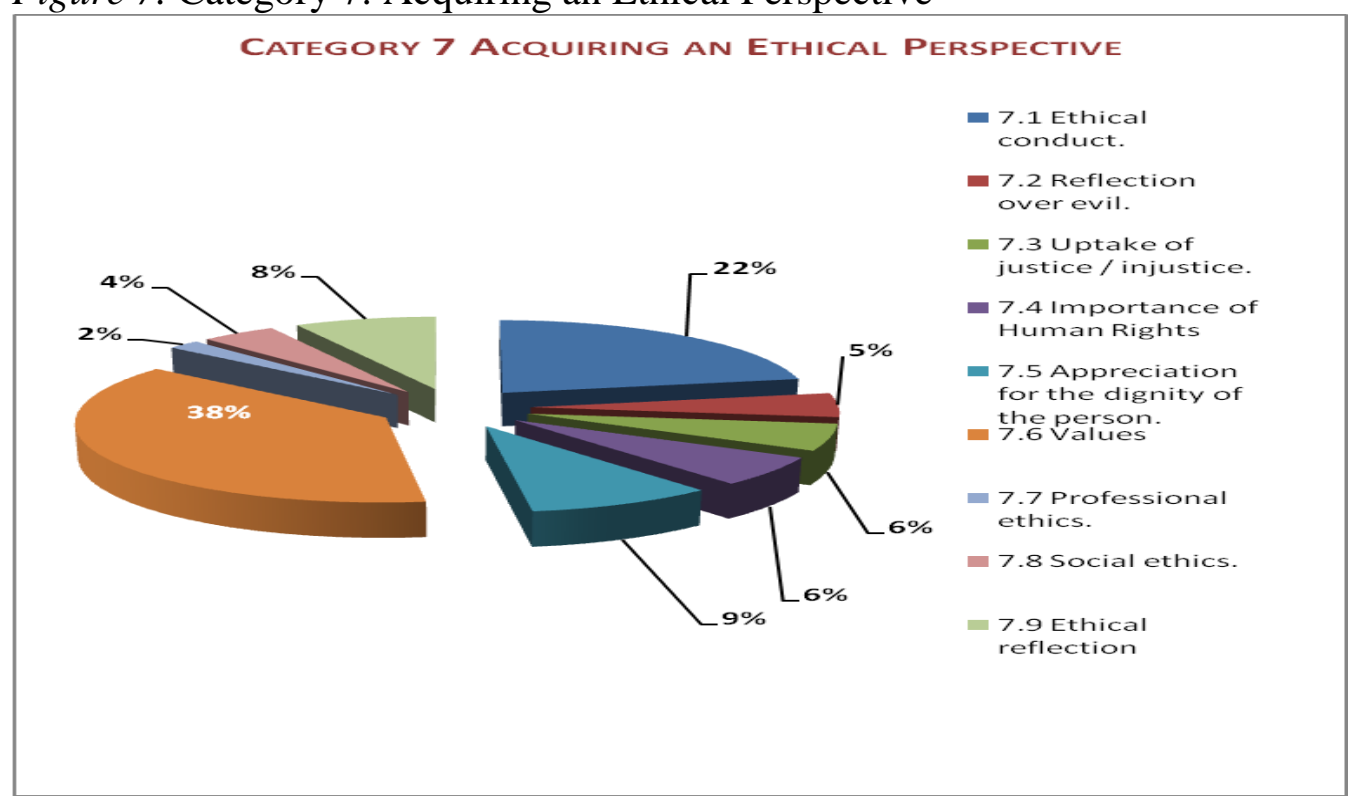

\section{Category 8: Developing Critical Thinking}

\section{"(...) This course made me go beyond my own thoughts"}

(Anonymous student's response)

Developing critical thinking, as a category, received a total of 153 entries. It grouped those students expressions referred to the development of the abilities such as questioning, investigating, arguing, being reasonable, interpreting meanings, becoming aware and achieving autonomy of thought, among others.

Like the autonomous moral development, development of critical thinking is one of the priorities of liberal education, and it has been for centuries. To think critically allows individuals to take their own decisions, defend a reasoned perspective, be able to discuss and argue their points of view, and therefore, gaining critical thinking skills is in some way acquiring a more human stature.

As in the previous category, it is disturbing that students would have made so few mentions about critical thinking as one of the valuable lessons of liberal education courses they took. The information is shown graphically in Figure 8. 
Figure 8. Category 8: Developing Critical Thinking

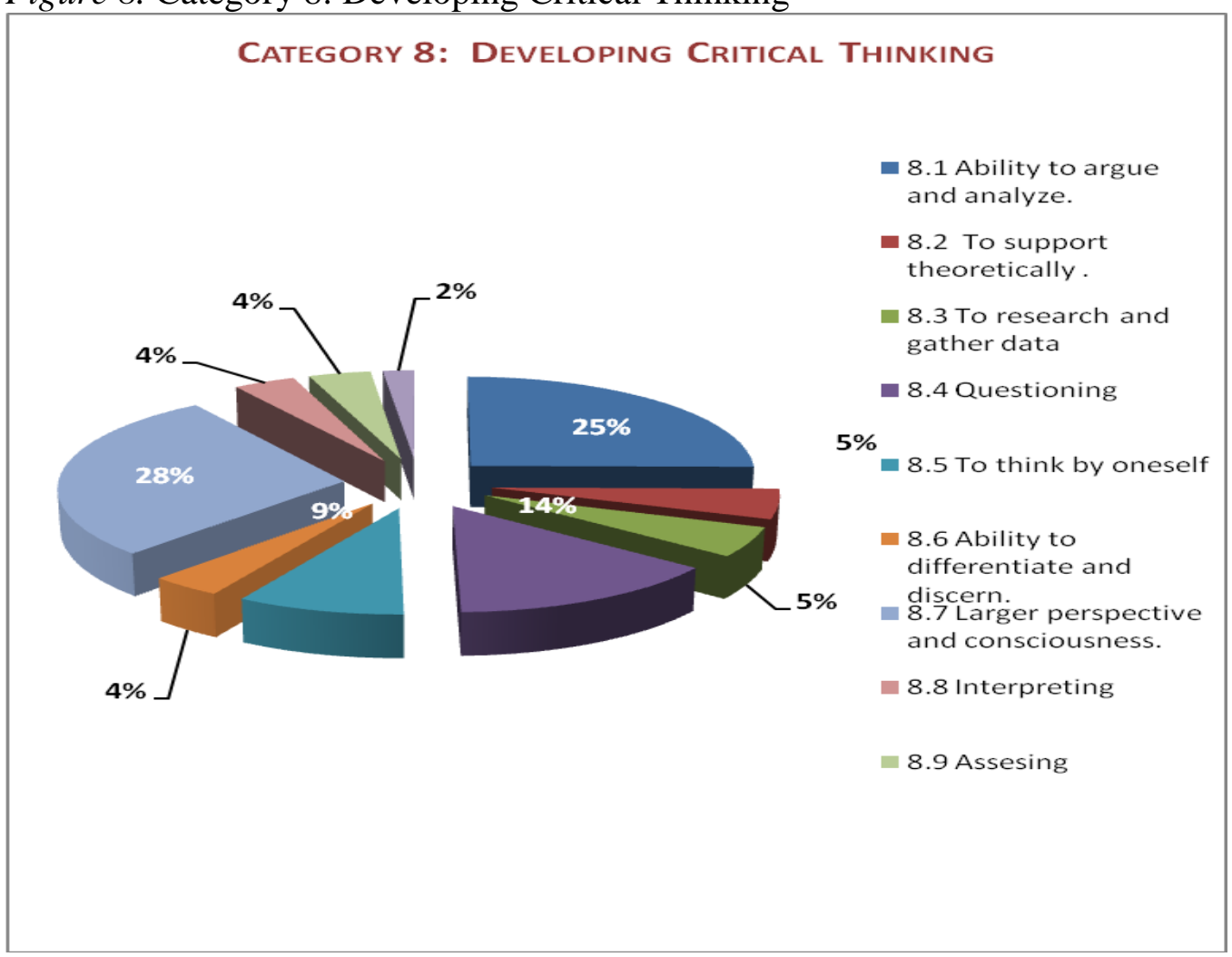

\section{Conclusions}

Regarding the qualitative analysis, two key conclusions of this study are as follows:

1. The three main areas of valuable learning for students consist of "Appreciating, respecting and learning about diversity"; "reflecting on oneself, the sense of life and the humanity", and, above all, "expanding knowledge and acquiring new perspectives from other disciplinary fields".

- It is valuable learning new knowledge. The students greatly appreciate the materials that allow them to expand their knowledge. Although they commonly complain of having to enroll in these courses that are not of "their career interest", yet they end up valuing the contribution of these courses to broaden their horizon of understanding, and therefore making them more able to interact differently with reality.

- Dialogue and participation promote appreciation and respect for diversity. The pedagogical method used in liberal education courses in Iberoamerican University, encourages an active participation and dialogue among students so that other ways of thinking and arguing could be learned. Also, the method seeks to promote respect and appreciation of different opinions and to develop tolerance. This 
teaching intentionality is reflected very clearly in what students value most. Very often, they found valuable to learn the ability to interact with others with tolerance and respect. In addition, students not only learn other points of view, but also they manage to consolidate their own knowledge and ideas through discussing different class issues.

- It is valuable reflecting on oneself and the meaning of life. Human beings wonder about the meaning of life and recognize that life it is fragile and vulnerable, but they realize that they can make sense of their life and move on. When we reflect on the human being with a methodology involving the individual itself, it is noteworthy that there is a change in students because they learn to gain a deeper understanding of themselves, and this, in turn, leads them to think not only in their own present or past, but also about their future, and therefore, to take responsibility for their own existence and even enjoy life and appreciate the present moment, among other things.

- One of the major tasks of human beings is learning about themselves. This implies grasping their past and present in order to shape the future. Through the pedagogical methodology, students achieve certain degree of introspection and to recognize their own strengths and weaknesses, so they can continue building their identity, which is a long lasting task. Among the topics covered in the courses, students highlight the emotional intelligence and the recognition and correction of errors as valuable learning.

2. Although students mentioned as valuable learning the possibility they had to interact with student of different disciplinary fields, developing a sense of social commitment, acquiring an ethical perspective and promoting critical thinking, these are aspects that deserve to be worked out better in courses. Liberal education certainly encourages the development of an ethical perspective, critical thinking and social commitment in a very important way, so it is disturbing that these aspects would have been left so behind in the students' assessment of valuable learning in the liberal education courses.

\section{Research Team}

1. Guillermo Alfaro Telpalo, M.S.

2. Mónica Chávez Aviña, M.S.

3. Andrés Navarro Zamora, M.S. 


\section{Acknowledgements}

We wish to thank, in first place, Prof. José Alberto Segrera Tapia, M.S., who was responsible for the final review of the document. His valuable comments and careful corrections helped to bring uniformity and consistency to the text.

Our Thanks also to Prof. Karime Haua, M.S., who was in charge of processing and reporting statistical information in the quantitative part of the study.

Our thanks to Prof. Manuel Ulloa, M.S., who worked as an external consultant in the interpretation and coding of categories in the qualitative part of the study.

Our thanks to Dr. José Sánchez Zariñana, S.J., who collaborated in the initial stage of the study.

Our thanks to Prof. Sylvia Schmelkes, M.S. Former Director of the Institute for Research and Development of Education at the Universidad Iberoamericana, which provided the financial resources to conduct this research.

Our thanks to Prof. Jose Ramon Ulloa Herrero,M.S., Director of Services for Integral Education at the Universidad Iberoamericana, who gave us all the facilities to carry out this study.

Finally, our deepest gratitude to all the professors who, through their daily work, make liberal education a valuable learning experience for all students.

\section{References}

Bain, K. (2004). What the best college teachers do. Cambridge: Harvard University Press.

Biggs, J. (2008). Calidad del aprendizaje universitario [Quality of university learning]. Madrid: Narcea.

López Calva, M. (1996). El humanismo en la práctica docente [Humanism in teaching]. Puebla: Universidad Iberoamericana Golfo Centro.

Marton, F. \& Säljö, R. (1976a). On the qualitative difference in learning I-Outcome and Process. British Journal of Educational Psychology, 46, 4-11.

Marton, F. \& Säljö, R (1976b). On the qualitative difference in learning II-Outcome as a function of the Learner's conception of the task. British Journal of Educational Psychology, 46, 115-127.

Marton, F., Hounsell, D. \& Entwistle, N. (1984) (Eds.). The experience of learning. Edinburgh. Scottish Academic Press.

Morin, E. (2001). Los siete saberes necesarios para la educación del future [The seven necessary knowledges for the education of the future]. Barcelona: Paidós. 